\title{
Control de constitucionalidad de los tratados. Análisis y comentarios del fallo del Tribunal Constitucional de 25 de agosto de $2009^{1}$
}

Este comentario, junto a los documentos que analiza, está disponible en www.anuariocdh.uchile.cl

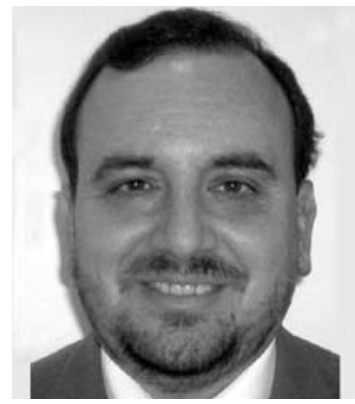

\section{Claudio Troncoso Repetto}

Abogado. Licenciado en Ciencias Jurídicas y Sociales, Universidad de Chile. LL.M Universidad de Heidelberg (Alemania). Profesor de Derecho Internacional de la Universidad de Chile.

ctroncosorepetto@hotmail.com

\section{RESUMEN}

El asunto debatido en la sentencia del TC, que es objeto de este artículo, es si el Tribunal Constitucional puede, luego de la reforma constitucional de 2005, ejercer o no un control represivo o ex post de la constitucionalidad de los tratados internacionales. Los órganos colegisladores concluyeron que no era posible que el TC ejerciera dicho control represivo, por lo que aprobaron una regla que establecía la inadmisibilidad de la acción de inaplicabilidad de las disposiciones de un tratado internacional. El TC, en fallo dividido, declaró inconstitucional tal regla, lo que es objeto del comentario crítico del presente artículo.

\section{Introducción}

El 25 de agosto de 2009 el Tribunal Constitucional (TC), de conformidad con el artículo 93 inciso primero $N^{\circ} 1$ de la Constitución Política de la República $(\mathrm{CPR})^{2}$, resolvió sobre la constitucionalidad del proyecto de ley que modificaba su propia ley orgánica constitucional ${ }^{3}$.

\footnotetext{
Sobre este tema véanse los artículos de opinión publicados en el diario "El Mercurio": "Un fallo del TC sujeto a la crítica" de los Profesores de Derecho Internacional Edgardo Riveros Marín, Hugo Llanos Mansilla, Claudio Troncoso Repetto, Alberto Rioseco Vásquez, Edmundo Vargas Carreño, Astrid Espaliat Larson, Fernando Gamboa Serazzi, Samuel Fernández Illanes y Álvaro Arévalo Cunich, el día 22 de septiembre de 2009 y "Constitución y tratados" del Doctor en Derecho Teodoro Ribera Neumann, Universidad Autónoma de Chile, el 29 de septiembre de 2009. Asimismo véanse los artículos de NOGUEIRA, Humberto. Las mutaciones de la Constitución producidas por vía interpretativa del Tribunal Constitucional. ¿El Tribunal Constitucional, poder constituido respetuoso de la Constitución o poder constituyente en sesión permanente? Estudios Constitucionales. Año 7, № 2. Universidad de Talca, 2009, pp. 389-427; NOGUEIRA, Humberto. Reforma constitucional de 2005 y control de la constitucionalidad de los tratados internacionales. Estudios Constitucionales. Año 5 N 1, Universidad de Talca, 2007; y de GARCíA, Ana María. Informe en Derecho. Control de la constitucionalidad de los tratados internacionales con especial referencia al control represivo. Estudios Constitucionales. Año $5 \mathrm{~N}^{\circ}$ 1. Universidad de Talca, 2007, pp. 469 a 480.

2 Artículo 93. "Son atribuciones del Tribunal Constitucional: $1^{\circ}$ Ejercer el control de constitucionalidad de las leyes que interpreten algún precepto de la Constitución, de las leyes orgánicas constitucionales y de las normas de un tratado que versen sobre materias propias de estas últimas, antes de su promulgación".

3 TC rol 1.288-2008.
} 
El artículo 47 B del proyecto de modificación de la ley orgánica constitucional del Tribunal Constitucional establecía que "[d]e conformidad con el número 1) del artículo 54 de la Constitución Política de la República, no procederá la inaplicabilidad respecto de tratados internacionales ratificados por Chile y que se encuentren vigentes"; y el artículo 47 G señalaba que "[p]rocederá declarar la inadmisibilidad en los siguientes casos: $4^{\circ}$ Cuando se promueva respecto de un precepto que no tenga rango legal o respecto de disposiciones de un tratado internacional vigente".

La reforma constitucional del año 2005 introdujo dos modificaciones al artículo 54 №1 de la CP, el cual actualmente señala que "[l]a aprobación de un tratado requerirá, en cada Cámara, de los quórums que corresponda, en conformidad al artículo 66, y se someterá, en lo pertinente, a los trámites de una ley. [...] Las disposiciones de un tratado sólo podrán ser derogadas, modificadas o suspendidas en la forma prevista en los propios tratados o de acuerdo a las normas generales de derecho internacional"4.

Igualmente, el artículo 93 de la CP en sus numerales 1 y $3^{5}$ consagra en forma expresa el control preventivo de constitucionalidad de los tratados internacionales. Este control puede ser facultativo respecto de un tratado sometido a la aprobación del Congreso u obligatorio en caso que las normas del tratado internacional versen sobre materias de leyes orgánicas constitucionales. Los numerales 6 y $7^{6}$ del mismo artículo se refieren a las facultades del Tribunal para ejercer control represivo de constitucionalidad de preceptos legales, ya sea por la vía de la inaplicabilidad de un precepto

4 Artículo 54. "Son atribuciones del Congreso: (1) Aprobar o desechar los tratados internacionales que le presentare el Presidente de la República antes de su ratificación. La aprobación de un tratado requerirá, en cada Cámara, de los quórums que corresponda, en conformidad al artículo 66, y se someterá, en lo pertinente, a los trámites de una ley. El Presidente de la República informará al Congreso sobre el contenido y el alcance del tratado, así como de las reservas que pretenda confirmar o formularle. El Congreso podrá sugerir la formulación de reservas y declaraciones interpretativas a un tratado internacional, en el curso del trámite de su aprobación, siempre que ellas procedan de conformidad a lo previsto en el propio tratado o en las normas generales de derecho internacional. Las medidas que el Presidente de la República adopte o los acuerdos que celebre para el cumplimiento de un tratado en vigor no requerirán de nueva aprobación del Congreso, a menos que se trate de materias propias de ley. No requerirán de aprobación del Congreso los tratados celebrados por el Presidente de la República en el ejercicio de su potestad reglamentaria. Las disposiciones de un tratado sólo podrán ser derogadas, modificadas o suspendidas en la forma prevista en los propios tratados o de acuerdo a las normas generales de derecho internacional. Corresponde al Presidente de la República la facultad exclusiva para denunciar un tratado o retirarse de él, para lo cual pedirá la opinión de ambas Cámaras del Congreso, en el caso de tratados que hayan sido aprobados por éste. Una vez que la denuncia o el retiro produzca sus efectos en conformidad a lo establecido en el tratado internacional, éste dejará de tener efecto en el orden jurídico chileno. En el caso de la denuncia o el retiro de un tratado que fue aprobado por el Congreso, el Presidente de la República deberá informar de ello a éste dentro de los quince días de efectuada la denuncia o el retiro. El retiro de una reserva que haya formulado el Presidente de la República y que tuvo en consideración el Congreso Nacional al momento de aprobar un tratado, requerirá previo acuerdo de éste, de conformidad a lo establecido en la ley orgánica constitucional respectiva. El Congreso Nacional deberá pronunciarse dentro del plazo de treinta días contados desde la recepción del oficio en que se solicita el acuerdo pertinente. Si no se pronunciare dentro de este término, se tendrá por aprobado el retiro de la reserva. De conformidad a lo establecido en la ley, deberá darse debida publicidad a hechos que digan relación con el tratado internacional, tales como su entrada en vigor, la formulación y retiro de reservas, las declaraciones interpretativas, las objeciones a una reserva y su retiro, la denuncia del tratado, el retiro, la suspensión, la terminación y la nulidad del mismo. En el mismo acuerdo aprobatorio de un tratado podrá el Congreso autorizar al Presidente de la República a fin de que, durante la vigencia de aquél, dicte las disposiciones con fuerza de ley que estime necesarias para su cabal cumplimiento, siendo en tal caso aplicable lo dispuesto en los incisos segundo y siguientes del artículo 64, y 2) Pronunciarse, cuando corresponda, respecto de los estados de excepción constitucional, en la forma prescrita por el inciso segundo del artículo 40".

5 Artículo 93. "Son atribuciones del Tribunal Constitucional: № 3 Resolver las cuestiones sobre constitucionalidad que se susciten durante la tramitación de los proyectos de ley o de reforma constitucional y de los tratados sometidos a la aprobación del Congreso".

6 Artículo 93. "Son atribuciones del Tribunal Constitucional: № 6 Resolver, por la mayoría de sus miembros en ejercicio, la inaplicabilidad de un precepto legal, cuya aplicación en cualquier gestión que se siga ante un tribunal ordinario o especial, resulte contraria a la Constitución. № 7 Resolver, por la mayoría de los cuatro quintos de sus integrantes en ejercicio, la inconstitucionalidad de un precepto legal declarado inaplicable en conformidad a lo dispuesto en el numeral anterior". 
legal en cualquier gestión que se siga ante un tribunal ordinario o especial resulte contraria a la Constitución, o por la vía de la inconstitucionalidad de un precepto legal declarado inaplicable. En el primer caso con efectos particulares para el caso concreto (inaplicabilidad) y en el segundo con efectos generales, de carácter derogatorio de la norma (inconstitucionalidad).

La discusión que subyace a la modificación de la ley orgánica y la posterior sentencia del Tribunal Constitucional consistió en determinar si las potestades que la Constitución Política -reformada el año 2005- le confiere al Tribunal Constitucional le permitían ejercer, además de un control preventivo, uno de tipo represivo (ex post) de la constitucionalidad de las disposiciones contenidas en un tratado internacional.

Los órganos colegisladores concluyeron que, conforme a las disposiciones antes señaladas de la Constitución Política, no era admisible que el Tribunal Constitucional pudiera ejercer un control represivo de constitucionalidad de los tratados internacionales, por lo que despacharon el proyecto de ley que modificaba la ley orgánica constitucional del Congreso Nacional, disponiendo expresamente en que no procedía la inaplicabilidad respecto de los tratados internacionales ratificados por Chile y que se encontraran vigentes. Además, se agregó en el artículo $47 \mathrm{G} \mathrm{N}^{\circ} 4$ que el tribunal procederá a declarar la inadmisibilidad "cuando se promueva (la cuestión) respecto de un precepto que no tenga rango legal o respecto de un tratado internacional vigente".

Estas disposiciones, en cuanto impedían que el Tribunal Constitucional pudiese declarar inaplicable las disposiciones de un tratado internacional vigente, fueron declaradas inconstitucionales por fallo de mayoría del Tribunal Constitucional.

A este respecto el Tribunal Constitucional declaró lo siguiente:

"3. Que el artículo 47 B y la frase 'o respecto de disposiciones de un tratado internacional vigente', comprendida en el artículo $47 \mathrm{G}$, inciso primero, $\mathrm{N}^{\circ} 4^{\circ}$, que el artículo único, $\mathrm{N}^{\circ} 57$, del proyecto remitido incorpora a la Ley $\mathrm{N}^{0} 17.997$, son inconstitucionales y deben eliminarse de su texto" ${ }^{\prime 7}$.

En cambio, fue considerada conforme con la Constitución el inciso final del artículo $47 \mathrm{O}$ (actual Art. $47 \tilde{\mathrm{N}}$ inciso $2^{\circ}$ de la Ley $\left.\mathrm{N}^{\circ} 20.381\right)^{8}$ que dispone que en el caso del artículo $93 \mathrm{~N}^{\circ} 7^{9}$ no podrá promoverse cuestión de constitucionalidad respecto de un tratado o una más de sus disposiciones.

En lo sucesivo, revisaré los principales argumentos de los votos de mayoría y de disidencia respecto de los temas que centran el debate argumentativo: (1) si por "precepto legal" debe entenderse sólo a las leyes internas del Estado o también debe incluirse en esta categoría las disposiciones de un tratado internacional vigente; y, (2) si una interpretación amplia del término "precepto legal" que habilite al Tribunal Constitucional para declarar inaplicable una disposición de un tratado internacional ratificado y vigente, importa o no una infracción a las disposiciones del artículo 54 $N^{0} 1$ ya señaladas. Finalmente haré un comentario a la sentencia.

7 TC rol 1.288-2008, punto resolutivo tres, pp. 75 y 76 . Énfasis añadido.

8 Artículo 47 Ñ.- En el caso del número $7^{\circ}$ del artículo 93 de la Constitución Política de la República, la cuestión de inconstitucionalidad podrá ser promovida por el Tribunal Constitucional actuando de oficio y por las personas legitimadas a que se refiere el inciso duodécimo del mismo artículo. Esta cuestión no podrá promoverse respecto de un tratado ni de una o más de sus disposiciones.

9 Artículo 93. Son atribuciones del Tribunal Constitucional: № 7 Resolver por la mayoría de los cuatro quintos de sus integrantes en ejercicio la inconstitucionalidad de un precepto legal declarado inaplicable en conformidad a lo dispuesto en el número anterior. 


\section{Tratados internacionales y el concepto de "precepto legal"}

\section{a. Argumentos del voto de mayoría}

Los autores del voto de mayoría ${ }^{10}$ afirman que luego de la reforma constitucional de 2005 el TC efectúa dos órdenes de controles respecto de los tratados internacionales: uno de carácter preventivo/obligatorio de las normas de un tratado que versen sobre materias propias de leyes orgánicas constitucionales y otro ex post y concreto/facultativo de constitucionalidad de una norma de un tratado que, en cuanto "precepto legal", pueda resultar contraria a la Constitución en su aplicación en "cualquier gestión que se siga ante un tribunal ordinario o especial"11.

Entienden, entonces, la expresión "precepto legal" en un sentido amplio, incluyendo en ésta las disposiciones de un tratado internacional. A pesar de reconocer que un tratado internacional no es lo mismo que una ley (admitiendo la intervención del derecho internacional tanto en la formación como en la derogación de los tratados), concluyen que esto no impide que puedan asimilarse y que ambos queden comprendidos en la categoría de "precepto legal"12.

Esta tesis se apoya en la reforma constitucional que permitió la ratificación del Estatuto de Roma de Corte Penal Internacional, afirmando que la necesidad de haber reformado la Carta Fundamental en forma previa a la aprobación de dicho tratado, tal como lo exigió en su momento el fallo que sobre esa materia emitió el Tribunal Constitucional, prueba que un tratado internacional tiene rango inferior a la Constitución, esto es, rango de ley y que sus preceptos pueden ser requeridos de inaplicabilidad.

Además se apoyan en las disposiciones de la Constitución que requieren la aprobación del Congreso respecto de los tratados que contengan materias de ley en conformidad a lo establecido en el artículo $54 \mathrm{~N}^{\circ} 1$ inciso $4^{\circ}$ de la Constitución, como aquellas referidas al control preventivo de constitucionalidad que el tribunal Constitucional ejerce respecto de las normas de un tratado que versen sobre materias de leyes orgánicas constitucionales. A este respecto, concluyen que "si el tratado no es una ley en sentido estricto, pero puede contener disposiciones propias de ley, tales disposiciones serán sin lugar a dudas 'preceptos legales' que pueden perfectamente ser objeto de un requerimiento por inconstitucionalidad"13.

\section{b. Argumentos del voto disidente}

Los autores del voto disidente ${ }^{14}$ hacen referencia a que antes de la Reforma Constitucional de 2005, el TC en su jurisprudencia había venido desvirtuando la asimilación entre "ley" y "tratado", declarando que "son fuentes de derecho diferentes" ${ }^{15}$. En este sentido, advierten que el

10 Ministros Raúl Bertelsen, Marcelo Venegas, Hernán Vodanovic, Jorge Correa y Enrique Navarro. El Ministro Navarro, sin perjuicio de concurrir a lo declarado en la parte resolutiva tercera de la sentencia y a lo razonado sobre el particular, fue de la opinión de que la norma contenida en el proyecto de ley (artículo 47 B) es inconstitucional por tratarse de una disposición interpretativa que no cumple con las exigencias establecidas en la Constitución para la validez de las mismas. En su opinión el constituyente puede, por la vía de una reforma constitucional, excluir a los tratados internacionales de la acción de inaplicabilidad. Lo anterior, agrega, sin perjuicio de lo previsto en el artículo 5 inciso 2 de la Constitución. Ver voto particular del Ministro Sr. Navarro, apartado IV titulado "Disposición de carácter interpretativo, en materia de tratados internacionales, en relación con la acción de inaplicabilidad". El Ministro Mario Fernández Baeza concurre a la sentencia adoptada por la mayoría con las prevenciones a que hace alusión en su voto particular.

11 Considerando cuadragésimo primero.

12 Considerando cuadragésimo séptimo.

13 Considerandos cuadragésimo noveno, quincuagésimo tercero y quincuagésimo cuarto.

14 Presidente del Tribunal, Ministro Juan Colombo Campbell y los Ministros José Luis Cea Egaña y Marisol Peña Torres.

15 Letra i del voto disidente. 
Constituyente de 1980 distinguió la ley del tratado dentro de las fuentes del derecho imperantes en Chile. Si ambos tipos de normas tuvieren la misma naturaleza habría bastado con utilizar la expresión genérica "ley". En este sentido, afirman que la reforma constitucional de 2005 sólo reafirmó esta tendencia al incorporar expresamente a las normas de un tratado internacional que versen sobre materias propias de leyes orgánicas constitucionales al control preventivo obligatorio del Tribunal Constitucional, ya que si fuesen lo mismo ley y tratado habría bastado con la referencia que existía ya en la Constitución a las leyes orgánicas constitucionales ${ }^{16}$. Finalmente, refuerzan la premisa de que la expresión "precepto legal" no puede hacerse extensiva a los tratados internacionales, acudiendo a la reforma constitucional de 2005 que introdujo la expresión "en lo pertinente" al referirse a los trámites de una ley a los que se sometería la aprobación de un tratado internacional ${ }^{17}$.

\section{Efectos de la declaración de inaplicabilidad respecto a las disposiciones de un tratado inter- nacional con relación al derecho internacional y las disposiciones del Art. $54 \mathbf{N}^{0} 1$ de la CP}

\section{a. Argumentos del voto de mayoría}

Los autores del voto de mayoría distinguen los efectos de la declaración de inconstitucionalidad de un tratado en el ejercicio del control preventivo de constitucionalidad, de los de la declaración de inaplicabilidad de la norma de un tratado vigente, señalando que en el primer caso la disposición declarada inconstitucional "no podrá formar parte del tratado que finalmente ratifique el Presidente de la República"18, mientras que en el segundo caso dicha declaración solo "producirá un efecto particular en el orden interno y para el caso concreto, sin que se altere la generalidad del tratado ni su vigencia desde el punto de vista del derecho internacional"19.

Descartan de esta forma que la declaración de inaplicabilidad de un precepto de un tratado internacional tenga un efecto derogatorio de dicha disposición -que es precisamente lo que prohíbe el Constituyente- puesto que sólo produce efectos particulares en la gestión pendiente concreta en que incide, en la cual el Juez no podrá aplicar dicho precepto ${ }^{20}$.

Formulan un distingo entre la situación anterior -en que la norma jurídica sigue vigente, sólo que inaplicable en una gestión determinada- y la de la declaración de inconstitucionalidad de un precepto legal por parte del Tribunal Constitucional, pues en este último caso se genera el mismo efecto de una ley derogatoria, esto es, expulsar al precepto legal del ordenamiento jurídico. Esto último implicaría una vulneración de las normas de derecho internacional y una infracción a las disposiciones constitucionales ${ }^{21}$.

Por último, resaltan que la inaplicabilidad es una forma de control concreto y no abstracto de constitucionalidad, ya que lo que puede ser declarado inconstitucional es la aplicación del precepto legal impugnado, lo que estiman es diferente a las atribuciones del Poder Legislativo de acuerdo al Art. $54 \mathrm{~N}^{\circ} 1$ inciso $5^{\circ}$ de la Constitución ${ }^{22}$.

\footnotetext{
16 Letras k) y l) del voto disidente.

17 Letra o) del voto disidente.

18 Entendemos que se refieren, aunque no lo explicitan, al control preventivo obligatorio de las normas de un tratado que versen sobre materias propias de ley orgánica constitucional.

19 Considerando cuadragésimo segundo.

20 Considerando quincuagésimo sexto.

21 Considerando quincuagésimo octavo.

22 Considerando sexagésimo y sexagésimo primero.
} 


\section{b. Voto particular del Ministro Mario Fernández Baeza ${ }^{23}$}

El Ministro Fernández Baeza fundamenta su voto particular en que "la inaplicabilidad no afecta a la norma sino a los efectos de su aplicación a un caso concreto"24. Distingue esta situación de la inconstitucionalidad ${ }^{25}$ pues la norma (como tal) no sería afectada, sino que simplemente no se aplicará por el tribunal al caso concreto, por lo que se mantiene totalmente vigente para todos los efectos jurídicos.

Tampoco se encontraría, a su juicio, afectada la buena fe del Estado de Chile ante sus contrapartes internacionales. La inaplicabilidad de una de sus normas a un caso concreto sin afectar su existencia y vigencia no altera la plena validez del tratado entre las partes ${ }^{26}$.

Refuerza su argumentación recurriendo al derecho comparado alemán y español ${ }^{27}$.

\section{c. Voto disidente}

Los autores del voto de minoría comienzan explicando el sentido del inciso quinto del artículo $54 N^{0} 1$ de la Constitución, según el cual "las disposiciones de un tratado sólo podrán ser derogadas, modificadas o suspendidas en la forma prevista en los propios tratados o de acuerdo a las normas generales de derecho internacional". A este respecto, acudiendo la historia fidedigna de su establecimiento, concluyen que con ella "se apuntaba a evitar que Chile incurriera en responsabilidad internacional si hacía primar su normativa interna por sobre un tratado vigente vulnerando las obligaciones derivadas de éste". Este argumento guarda coherencia con lo dispuesto en los artículos $26^{28}$ y $27^{29}$ de la Convención de Viena sobre Derecho de los Tratados, en orden a cumplir de buena fe las obligaciones contenidas en los tratados internacionales (pacta sunt servanda) y a la prohibición de invocar las disposiciones de derecho interno como justificación del incumplimiento de los tratados, respectivamente ${ }^{30}$.

Descartan que la disposición del inciso $5^{\circ}$ del artículo 54 № 1 esté dirigida sólo al Presidente de la República y al Congreso Nacional y no a un órgano como el Tribunal Constitucional. Subrayan que la responsabilidad internacional se atribuye al Estado como un todo y no a determinados órganos y que, por tanto, la actuación del Tribunal Constitucional puede comprometer la responsabilidad internacional de Estado ${ }^{31}$.

A este respecto razonan que si se declara la inaplicabilidad de una norma de un tratado, el juez no podrá aplicar el precepto para resolver el asunto. Luego, la norma en cuestión queda

23 Voto particular del Ministro Sr. Mario Fernández Baeza apartado VI titulado "Los preceptos de los tratados internacionales pueden ser objeto de inaplicabilidad por inconstitucionalidad".

24 Número 33 de su voto particular.

25 Número 34 de su voto particular.

26 Número 35 de su voto particular.

27 A estos efectos cita el artículo 100 de la Ley Fundamental de Alemania y hace referencia a la doctrina en España citando a Manuel Diez de Velasco y mencionando los artículos 95, 161, 161 a y 163 de la Constitución de España y de diversas disposiciones de la Ley Orgánica del Tribunal Constitucional (LOTC) de ese país. Número 35 de su voto particular.

28 Convención de Viena sobre el Derecho de los Tratados. U.N. Doc A/CONF.39/27 (1969), 1155 U.N.T.S. 331.27 enero de 1980. Artículo 26. "Pacta sunt servanda". Todo tratado en vigor obliga a las partes y debe ser cumplido por ellas de buena fe.

29 Convención de Viena sobre el Derecho de los Tratados. Artículo 27. El derecho interno y la observancia de los tratados. Una parte no podrá invocar las disposiciones de su derecho interno como justificación del incumplimiento de un tratado. Esta norma se entenderá sin perjuicio de lo dispuesto en el artículo 46.

30 Letras p) y q) del voto disidente.

31 Letra r) del voto disidente. 
"suspendida" en su aplicación en la causa correspondiente, lo que constituye una transgresión al artículo 54, № 1 de la Carta Fundamental, pues la "suspensión" no está contemplada dentro de las disposiciones del tratado o las normas generales del derecho internacional. Finalmente, señalan que no resulta lógico impedir la declaración de inconstitucionalidad y permitir la de inaplicabilidad sólo porque en este último caso el efecto de la suspensión se circunscribe a una gestión concreta, ya que en ambos casos se vulnera la Constitución y se genera la responsabilidad internacional del Estado ${ }^{32}$.

\section{d. Voto disidente del Ministro Francisco Fernández Fredes}

El Ministro Fernández Fredes funda su voto disidente afirmando que la voluntad del constituyente, desde la reforma de 2005, es que las normas de un tratado internacional no sean susceptibles de control represivo de constitucionalidad, sino sólo de control preventivo, tanto facultativo como obligatorio, si (en este último caso) el tratado incluye normas propias de una ley orgánica constitucional. A su juicio esta es la única interpretación que se compadece con la letra y el espíritu de la Constitución y que mantiene la coherencia con el ordenamiento jurídico en su conjunto. Finalmente, indica que un eventual fallo del Tribunal Constitucional que acoja un requerimiento de inaplicabilidad contra una norma de un tratado vigente sería susceptible de impugnarse por una acción de nulidad de derecho público ${ }^{33}$.

\section{Comentarios respecto de la sentencia ${ }^{34}$}

Resulta de la mayor importancia para resolver el problema en cuestión, acudir al principio que la doctrina alemana conoce como "interpretación amigable con el derecho internacional"35. Dicho principio ha sido acogido por la doctrina chilena y por los tribunales nacionales, resultando de especial relevancia su recepción en la sentencia del Tribunal Constitucional respecto del Convenio N 169 de la OIT sobre pueblos indígenas al exponer el principio de interpretación que:

"se funda en la gravedad que entraña para un Estado, en el ámbito internacional, la declaración de inconstitucionalidad de las normas de un tratado, por un órgano jurisdiccional interno y se traduce en que el intérprete debe hacer todos los esfuerzos, dentro de lo permitido por la Ley Suprema del respectivo Estado, por encontrar una interpretación conciliatoria entre las normas de un Tratado y los preceptos de la Constitución" ${ }^{\prime 36}$.

32 Letras $u), v)$ y w) del voto disidente.

33 Letras e) f) y g) del voto disidente del Ministro Francisco Fernández Fredes.

34 Respecto de estos comentarios críticos ver el artículo de opinión publicado en el diario "El Mercurio", "Un fallo del TC sujeto a la crítica" de los Profesores de Derecho Internacional Edgardo Riveros Marín, Hugo Llanos Mansilla, Claudio Troncoso Repetto, Alberto Rioseco Vásquez, Edmundo Vargas Carreño, Astrid Espaliat Larson, Fernando Gamboa Serazzi, Samuel Fernández Illanes y Álvaro Arévalo Cunich, el día 22 de septiembre de 2009.

35 Völkerrechtfreundlichkeitprinzip. Una enunciación de este principio se puede encontrar en: Troncoso Repetto, Claudio: Die Rezeption der völkerrechtlichen Menschenrechte in der chilenischen Verfassug und im deutschen Grundgesetz. Magisterarbeit. Heidelberg, 1991. El Profesor Santiago Benadava enuncia un principio similar de la siguiente manera: "En estos casos el tribunal interno debe evitar el conflicto dando a la ley interna, si ello es posible, una interpretación que la concilie con las estipulaciones del tratado, pues, como hemos visto, hay que presumir que el legislador no ha pretendido dictar leyes contrarias a las obligaciones internacionales del Estado". En: BENADAVA, Santiago. Las relaciones entre derecho internacional y derecho interno ante los tribunales chilenos. Editorial Jurídica de Chile, 1992, p. 46.

36 Considerando $3^{\circ}$ de la sentencia del Tribunal Constitucional de 4 de agosto de 2000, recaída en el requerimiento formulado por diversos diputados para que el tribunal resuelva la constitucionalidad del Convenio № 169 , sobre Pueblos Indígenas y Tribales en Países Independientes, adoptado por la Organización Internacional del Trabajo, el 27 de junio de 1989, de acuerdo al artículo 82, № 2, de la Constitución Política de la República. Rol 309. 
El fallo adoptado por el Tribunal Constitucional no da respuesta al importante argumento contenido en el voto disidente referido al artículo 93 de la Carta Fundamental y las atribuciones del Tribunal Constitucional. El voto disidente señala que cuando la Constitución ha querido conferirle facultades para efectuar un control de constitucionalidad de los tratados internacionales al Tribunal Constitucional, lo ha hecho en forma expresa y no asimilándolos a "leyes", "proyecto de ley" o "precepto legal". Si bastara con asimilar el tratado internacional a un "precepto legal" carecería de sentido la mención expresa que el Constituyente hace a los tratados, o las disposiciones de éstos en los numerales 1 y 3 del artículo 93. Las referencias al derecho comparado no alteran la contundencia de este argumento, que además se refiere al texto constitucional chileno.

Igualmente, la asimilación de los tratados a un "precepto legal", en los términos del artículo 93 de la Constitución, genera la contradicción de que, en opinión del fallo del Tribunal Constitucional, opera sólo respecto de la inaplicabilidad y no de la inconstitucionalidad, en circunstancias que tanto en el numeral 6 (inaplicabilidad) como en el numeral 7 (inconstitucionalidad) del artículo 93 de la Carta Fundamental se alude a "precepto legal". Por lo tanto, en el numeral 6 el término "precepto legal" comprendería a los tratados internacionales y en numeral 7 el mismo término no tendría ese alcance. El voto de mayoría busca superar esta contradicción distinguiendo los efectos de la declaración de inaplicabilidad de los de la de inconstitucionalidad, para justificar el control represivo de constitucionalidad de los tratados en un caso y no en el otro, lo que, a mi juicio, esta distinción no tiene asidero ni en las normas constitucionales ni en las internacionales.

El criterio del voto de mayoría del Tribunal Constitucional de reconocer que un tratado no es lo mismo que una ley, pero que es asimilable a ella, no da cuenta de la verdadera naturaleza jurídica de los tratados internacionales, ni de su ubicación en el orden jerárquico normativo de nuestro derecho interno. Los argumentos que se utilizan para fundar este criterio -como son el relativo a la reforma constitucional que permitió la ratificación del Estatuto de Roma de la Corte Penal Internacional; el referido a que la Constitución aluda a los tratados que contengan materias propias de ley, para indicar que esos casos requieren de aprobación legislativa, no obstante tratarse de acuerdos celebrados para el cumplimiento de otros ya en vigor, o que la propia Carta Fundamental se refiera a las disposiciones de un tratado que versen sobre materias propias de las leyes orgánicas constitucionales para determinar en tales casos se exige el control preventivo obligatorio de constitucionalidad- no guardan relación con el rango de los tratados en el ordenamiento jurídico chileno. En efecto, la reforma constitucional relativa al Estatuto de Roma de la Corte Penal Internacional se hizo necesaria una vez que el propio Tribunal Constitucional declaró que ello era indispensable antes de aprobar y ratificar dicho tratado. De este hecho podría inferirse que los tratados internacionales, en su calidad de fuente formal de derecho ${ }^{37}$, están sometidos a la Constitución, pero no que tengan necesariamente rango legal. Tampoco la mención que hace la Constitución a los tratados que versan sobre materias de ley o las disposiciones de un tratado que versan sobre materias propias de leyes orgánicas constitucionales tiene relación con el rango de éstos en el orden jurídico chileno. Por el contrario, estas disposiciones buscan esclarecer cuáles tratados deben ser aprobados por el Congreso, y qué disposiciones de un tratado deben ser sometidas a control preventivo obligatorio de constitucionalidad por parte del Tribunal Constitucional, sin que ello transforme la naturaleza de los tratados en leyes internas, los cuales por lo demás deben ser considerados como una unidad independiente de las normas que contengan.

A mayor abundamiento, la doctrina y la jurisprudencia desde el siglo XX se han inclinado progresivamente hacia considerar que los tratados internacionales tienen un rango supralegal. A partir

37 Independiente del rango constitucional o supraconstitucional que poseen los derechos humanos contenidos en tratados internacionales, en virtud del artículo 5 inciso 2 de la Constitución. 
de la introducción del inciso $2^{\circ}$ del artículo 5 de la $\mathrm{CP}^{38}$, se ha reconocido por diversos autores y en numerosos fallos que los derechos humanos contenidos en tratados internacionales tienen una jerarquía si no supraconstitucional, al menos constitucional ${ }^{39}$.

En este sentido, cabe destacar que la tesis de otorgarle rango legal a los tratados se fundó originalmente en la disposición de la Constitución de 1925 que señalaba que los acuerdos tendrán en el Congreso los mismos trámites que una ley (artículo $43 \mathrm{~N}^{0}$ 5). Esta norma fue recogida en el texto constitucional de 1980 en los siguientes términos: "[l]a aprobación de un tratado se someterá a los trámites de una ley" (artículo 50 № 1). Precisamente para destacar la diferencia entre "tratado" y "ley", la reforma constitucional de 2005 dispuso que la aprobación de un tratado "se someterá en lo pertinente a los trámites de una ley"40.

En lo tocante a los efectos de las declaraciones de inaplicabilidad e inconstitucionalidad de los tratados internacionales, admitiendo las primeras y no las segundas, por el alcance limitado que aquéllas tienen al recaer en un caso concreto y para una gestión determinada y carecer de efecto general "erga omnes", cabe señalar que la vulneración a las obligaciones de un tratado en vigor no guarda relación con el alcance de una determinada decisión. Ya sea que se impida la aplicación del tratado internacional en un caso concreto y en una gestión determinada, bien con efectos generales, igualmente se está en presencia de un acto de un órgano del Estado que, al vulnerar las obligaciones internacionales, generará la responsabilidad internacional consiguiente para el Estado ${ }^{41}$. Esto es precisamente lo que el constituyente procuró impedir con la inclusión del inciso $5^{\circ}$ del artículo $54 \mathrm{~N}^{\circ} 1$ de la Constitución, tal como lo da cuenta la historia del establecimiento de dicha norma a que se refiere el voto de minoría, independiente de lo que se prevea en el derecho comparado sobre el particular.

Por último, ninguno de estos comentarios críticos a la decisión adoptada por el Tribunal Constitucional pone en duda la necesidad de velar por el cumplimiento del principio de supremacía constitucional. El problema de fondo es la oportunidad en que se ejerce el control de constitucionalidad. Si éste es preventivo, antes que el Estado exprese su consentimiento en obligarse por el tratado, no se produce infracción alguna al derecho internacional que pueda generar responsabilidad internacional para nuestro Estado. Si, por el contrario, es represivo (ex post) trae aparejada la consecuencia de la suspensión o derogación de un tratado en vigor para Chile (aunque sea para un caso particular) por un órgano interno del Estado, como es el Tribunal Constitucional, al margen de lo establecido en el propio tratado o en las reglas generales de derecho internacional. Si el problema es cómo ejercer un control más eficiente de la constitucionalidad de los tratados, los acentos deben estar en un examen más acucioso de la compatibilidad de los tratados con las disposiciones de nuestra Constitución en el período de negociación de los mismos o durante su aprobación legislativa, pudiendo incluso considerarse la posibilidad de extender el control preventivo obligatorio que establece nuestra Constitución a todos los tratados sometidos a aprobación del Congreso, mas no de permitir un control de constitucionalidad ex post de tratados vigentes.

38 Artículo 5, inc. $2^{\text {o: }}$ "El ejercicio de la soberanía reconoce como limitación el respeto a los derechos esenciales que emanan de la naturaleza humana. Es deber de los órganos del Estado respetar y promover tales derechos, garantizados por esta Constitución, así como por los tratados internacionales ratificados por Chile y que se encuentren vigentes".

39 Respecto a la prevalencia de los tratados internacionales sobre las leyes en el orden jurídico chileno puede consultarse el artículo de BENADAVA, Santiago. Las relaciones entre derecho internacional y derecho interno ante los tribunales chilenos. Editorial Jurídica de Chile, 1992, pp. 9 a 59. En lo relativo al rango de las normas de derechos humanos contenidos en tratados internacionales, véase el artículo de MEDINA, Cecilia. El derecho internacional de los derechos humanos y el ordenamiento jurídico chileno. En: Constitución, tratados y derechos esenciales. Corporación Nacional de Reparación y Reconciliación, 1994, pp. 3 a 54.

40 Artículo $54 \mathrm{~N}^{\circ}$ 1. Énfasis añadido. En este mismo sentido razona el voto disidente.

41 En este mismo sentido razona el voto de minoría. 
